
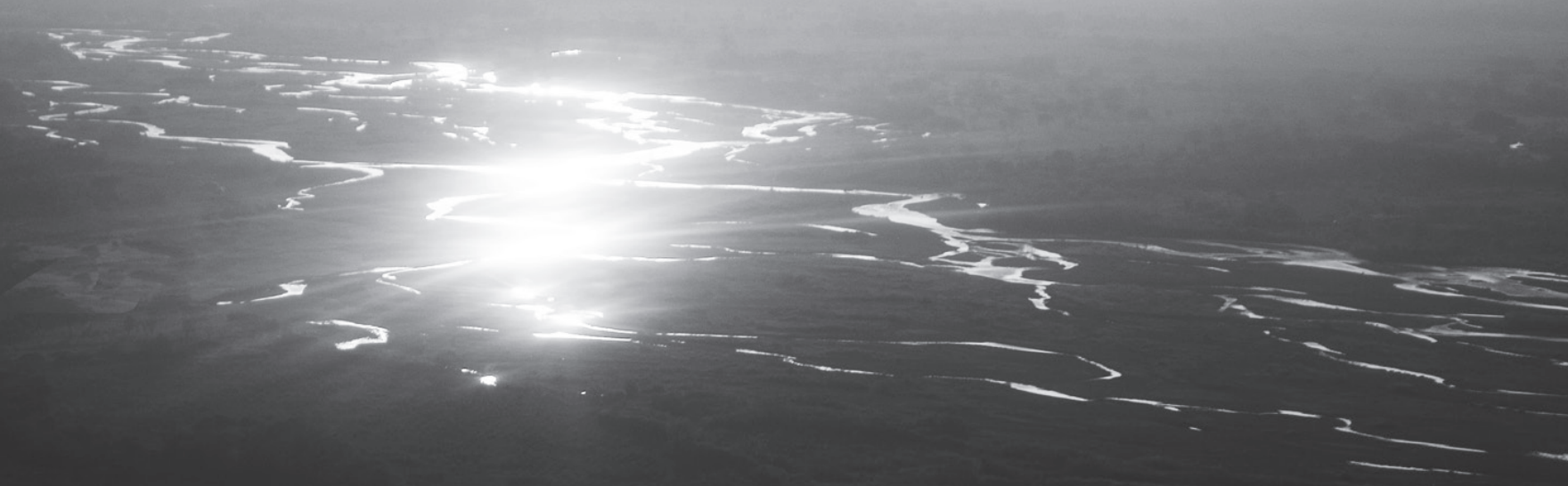

\title{
APUNTES SOBRE EL PROCESO DE INVESTIGACIÓN DEL DOCUMENTAL APAPORIS, SECRETOS DE LA SELVA ${ }^{1}$
}

NOTES ON THE RESEARCH PROCESS APAPORIS SECRETS OF THE JUNGLE, DOCUMENTARY

Por:

José Antonio Dorado Z. ${ }^{2}$

Profesor de la Escuela de Comunicación Social

Universidad del Valle

jose.dorado@univalle.edu.co

Resumen: Este artículo plantea una reflexión sobre el proceso de investigación y producción audiovisual, implementada en la experiencia del documental Apaporis, Secretos de la Selva. Es un texto escrito a posteriori, que reflexiona sobre los modos de investigar en el contexto de las artes audiovisuales.

Palabras clave: Amazonía, documental, estilística, forma fílmica, investigación.

Abstract: this article is a reflection on the research process and audiovisual production, implemented in the experience of the Apaporis Secrets Forest documentary. It is a post written text, which reflects on the modes of research in the context of visual arts.

Key words: Amazon, documentary, filmic form, research, stylistic. 
Los senderos de la investigación aplicada al documental audiovisual no corresponden a los artículos que abundan en revistas o publicaciones especializadas. Habitualmente quienes reflexionan y escriben sobre los documentales no necesariamente están preocupados por los procesos de investigación, o quienes se interesan en hacerlo desde una perspectiva teórica, no necesariamente han estado involucrados en las tareas de escribir y dirigir trabajos documentales. Los textos que predominan son propuestas reflexivas que desde una mirada externa y taxonómica clasifican los trabajos audiovisuales para comprender diferentes aspectos, como puede ser la estructura narrativa, el punto de vista, los contenidos explícitos e implícitos, los modos de representación conscientes e inconscientes. Todo esto analizado de manera focalizada y/o mezclada desde perspectivas tan diversas como los territorios disciplinares desde los cuales las películas son objetos de estudio.

El propósito de este trabajo es distinto, no se trata de inferir a través del resultado final, sino a partir del proceso de construcción de la propuesta audiovisual (en esa medida en algunos casos se narra en primera persona). Es de alguna manera, reconstruir la memoria de los diferentes peldaños que se llevaron a cabo para realizar el trabajo final, con el propósito de compar tir el gratificante proceso de investigación y realización, así como también el vértigo, los imprevistos y las incertidumbres que implica asumir este tipo de apuestas.

Debo advertir que no encontrarán la revelación de una fórmula secreta para investigar, o un modelo ideal para hacer documental en la selva o en América Latina. Sencillamente es una reflexión sobre el proceso de realización de un documental que ha tenido un gran impacto nacional e internacional, a través de diversos festivales y encuentros culturales ${ }^{3}$, pero que además tuvo una gran repercusión en Colombia, siendo a la fecha el documental que mayor cantidad de público ha

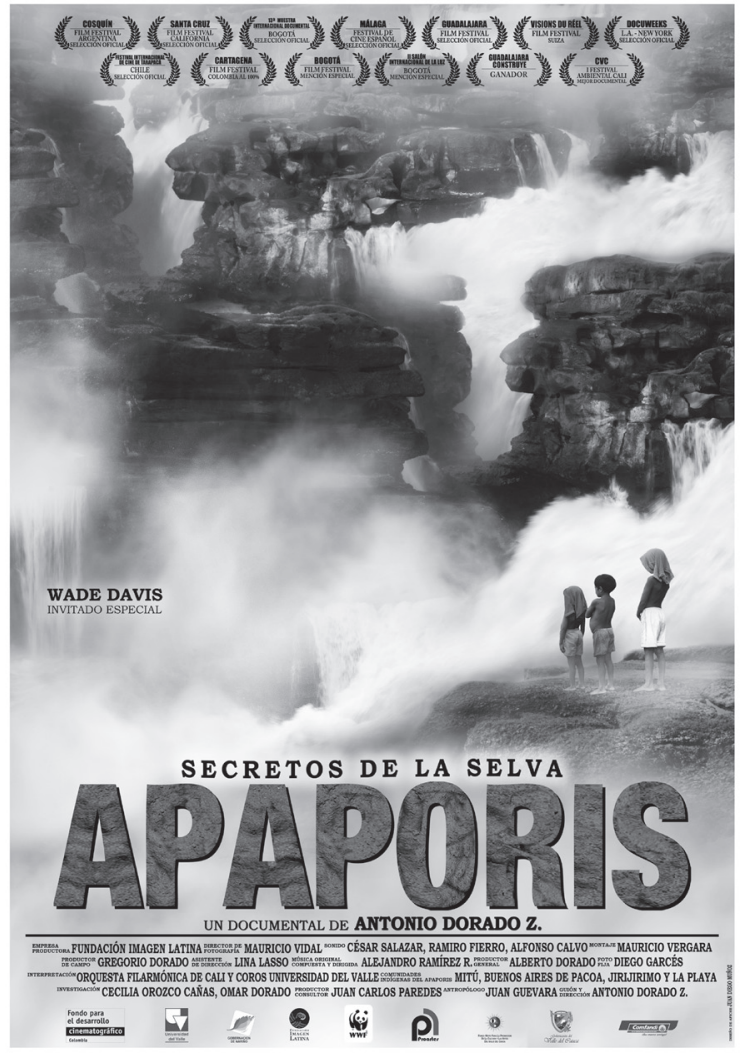
convocado en las salas de cine ${ }^{4}$.

Cada proyecto audiovisual traza su propio sendero, y en el caso del documental esa dialéctica permanente con el azar, le otorga un sentido especial, que hace que el proceso de investigación no corresponda estrictamente al proceso inicial que permite la escritura del proyecto, sino que la investigación sigue activa tanto en el rodaje como en la postproducción, e incluso en la distribución. En consecuencia más que fórmulas, pretendo compartir interrogantes, observaciones, ideas, dificultades, fracasos y dudas que enfrentamos en un largo proceso, que inició en el año 2005 y que culminó en el 2012. 
¿Cómo surgió el proyecto Apaporis, secretos de la selva? Después de haber hecho todo el periplo para realizar la película El Rey en el año 2004, quería poner en reposo el mundo de los gángsters criollos para hacer algo más cercano a nuestras raíces étnicas. El tema de las comunidades indígenas nunca ha sido ajeno a mis intereses. Nací en Bolívar (Cauca), un pequeño pueblo incrustado las montañas del macizo colombiano, donde confluyen los departamentos del Cauca, Putumayo y Nariño, y siempre había pensado emprender un proyecto sobre mis raíces étnicas. Sin embargo, debo confesar que no tenía claro el tema a desarrollar. En el 2005 estuve en algunos eventos con la película El Rey y al salir del Centro Cultural de Cali, Germán Patiño me dijo: hay un libro de Wade Davis que usted debería conocer. Recuerdo también que la primera persona que me habló del libro fue Hernán Toro: -Si me fuera a una isla, lejos de todo el mundo, El Río es uno de los diez libros que llevaría para leer-, me comentó con vehemencia. Parecía que el libro estaba utilizando a varias personas para que me hablaran de su existencia. Esto se ratificó cuando una amiga lo colocó en mis manos y me dijo: Aquí hay una historia extraordinaria. No sé si este acto simbólico determinó que me apropiara del libro o que el libro se apropiara de mí. Cuando lo empecé a leer, quedé atrapado en una historia que sobrepasaba mis expectativas. En cada capítulo sentía una especie de bofetada por la ignorancia que tenía sobre la sabiduría del conocimiento de nuestros botánicos ancestrales. Al llegar a las páginas finales, me llamó Juan Paredes, un amigo productor que vive en Los Ángeles, y me preguntó si tenía un nuevo proyecto. Le conté que me gustaría hacer una adaptación de un libro, que el autor es Wade Davis, uno de los cuatro exploradores de la National Geographic, y que además es el autor de La serpiente y El Arco Iris, el libro que compró Hollywood para adaptarlo al cine.

Una semana después, me llamó y me dijo: estoy en la línea con Wade Davis y te quiere hablar. Para mi sorpresa, me encontré con que este hombre estaba feliz de saber que un colombiano tuviera interés en hacer una película sobre su libro. Le comenté que era profesor de la Universidad del Valle, que había hecho algunos trabajos y le prometí que le enviaría una copia de una película que había realizado. Unos meses después fui a visitarlo a su casa en Washington. Cuando lo conocí sentí la complicidad de un ser humano muy sencillo y muy sabio. Era como si quisiera devolverme todas atenciones que le habían ofrecido en Colombia. Lo primero que me comentó era que le había encantado El Rey, porque le recordaba la ciudad de su adolescencia. El asunto es que Davis vino a Cali de intercambio, cuando tenía 14 años y aquí tuvo su primera novia, también Cali había sido un lugar de retornos permanentes en los años setenta cuando vino a probar todas las plantas de tóxicos y psicotrópicos que se encontraba en su camino. En la conversación Davis recordó que en la Universidad del Valle trabajaba el profesor Isidoro Cabrera ${ }^{5}$, que había sido asistente del profesor Richard Evan Shultes, y que le había concedido sendas entrevistas para la escritura de su libro El Río. Estas situaciones facilitaron el diálogo y la amistad. Davis generosamente me ofreció los derechos del libro por dos años para hacer una adaptación al cine. Le propuse que primero me interesaba hacer un documental, para conocer de cerca las comunidades, pues desconocía tanto la Amazonía como la gran mayoría de colombianos. Ya teniendo su aval inicié el proceso del proyecto, mi primera intención fue enviarlo a la Convocatoria de Dirección Cinematográfica del año $2006^{6}$ que empezaba a dar apoyo económico para este tipo de proyectos. 
Sabía que la clave de la propuesta era la investigación, pero ¿por dónde empezar? En cierta forma la propuesta involucraba un trabajo de adaptación, porque partíamos de una referencia literaria concreta, en la cual había muchos elementos de la investigación adelantada. Sin embargo, un asunto es la investigación que implícitamente tiene la escritura de un texto literario y otra es la investigación que estimula la realización de un filme. Es decir, el primer interrogante que me asaltaba era, ¿qué adaptación que asumiría?

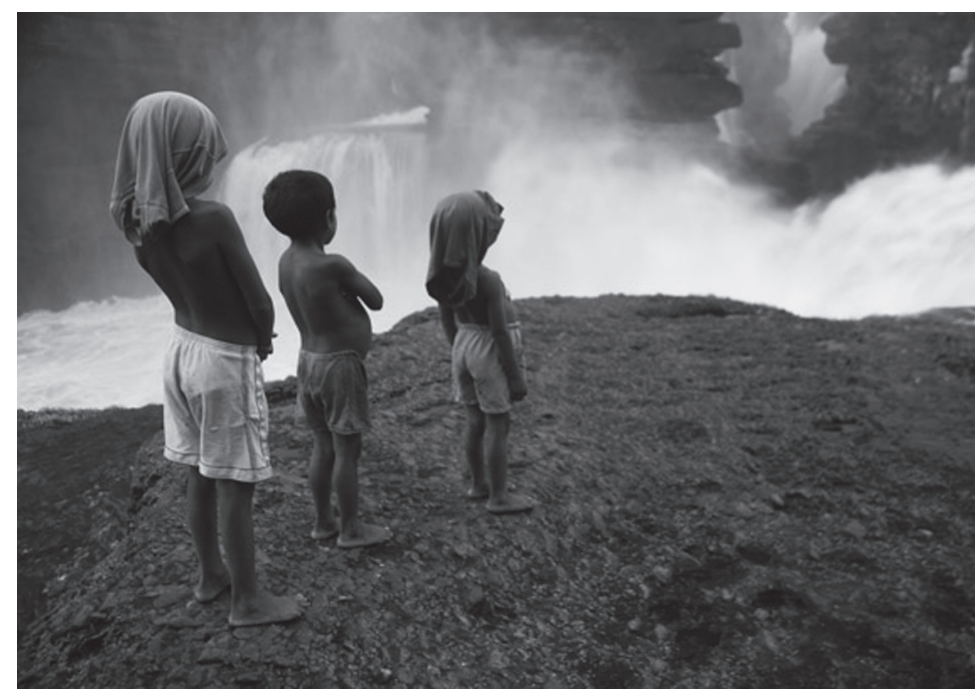

Este interrogante implicaba otras preguntas. ¿Retomaría el eje central de la narración literaria?, ¿qué asuntos centrales me interesaban? ¿Trabajaría sobre los personajes que aparecen consignados en la versión literaria? ¿Delimitaría los temas a partir de ciertos capítulos del texto? ¿De qué manera asumiría en el documental la propuesta de adaptación literaria de El Río?

En otras ocasiones me he ilustrado de los encuentros y desencuentros históricos entre el cine y la literatura ${ }^{7}$, una relación frecuente, necesaria y también peligrosa. Desde los primeros estudios académicos de George Bluestone, se marcan las diferentes posturas estéticas entre cine y literatura. Einsentein enfatizó que el sistema fílmico no tiene unidades mínimas permanentes de significado. Es evidente que el cine no tiene una gramática fija. Sus convenciones son distintas, inclusive en la puntuación. Lo que sí comparten el sistema escrito y el sistema fílmico es que tienen significado. Pero definitivamente por los medios a través de los cuales se trasmite el significado, los códigos cinematográficos son completamente diferentes a los códigos del lenguaje escrito, y están afianzados en otros sistemas que provienen de otras artes que no necesariamente dependen de la palabra. Esto implicaba asumir una reinterpretación de la propuesta escrita. Como en nuestro caso íbamos a realizar un documental que involucraba un recorrido sobre unos territorios selváticos, donde no pretendíamos hacer puestas en escena, tenía la posibilidad de asumir una postura libre frente a cualquier adaptación literaria. El libro marcaría unas referencias pero el audiovisual estaba obligado a encontrar su propio sendero. En ese camino poco a poco logré distanciarme de la adaptación y emprendí una propuesta audiovisual personal e independiente que pretendía exaltar el conocimiento indígena, que dialogaba e interactuaba sutilmente con el libro, con el propio Wade Davis, y sobre todo con los pueblos y comunidades indígenas de los territorios implicados.

Fotografías: Diego Miguel Garcés

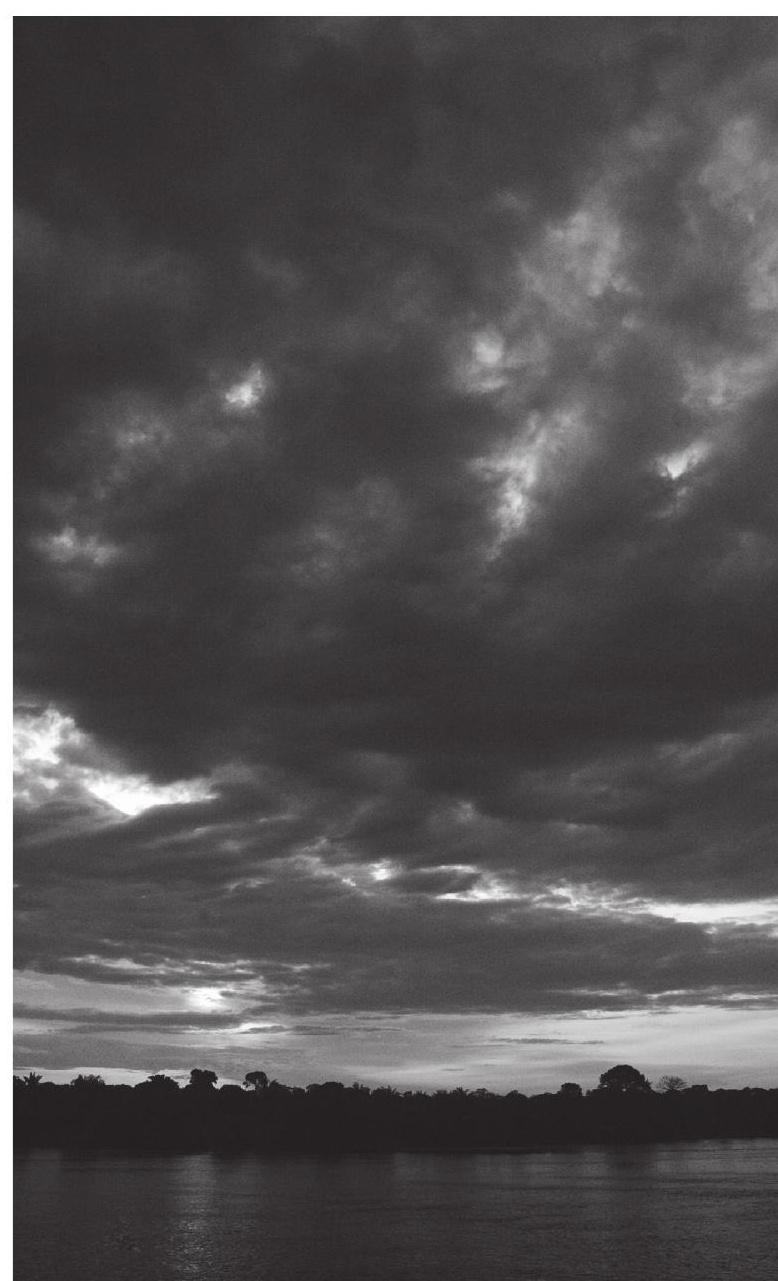


Sobre la investigación audiovisual, habitualmente siempre he trabajado en dos perspectivas: la investigación del objeto de estudio, propiamente dicho, y la investigación sobre el tratamiento estético audiovisual. Esta diferenciación es útil en la medida en que nos permite identificar dos ámbitos de indagación que podemos diferenciar; pero la diferenciación puede ser nociva si se asocia con las diferencias entre contenido y forma, porque se puede pensar que el contenido es lo más importante y la forma solo el empaque o el diseño de presentación. El oficio de la docencia me ha permitido conocer desde hace tiempo la lectura de El Arte Cinematográfico, escrito por David Bordwell y Kristin Thompson (1995). Los autores proponen la forma fílmica, que trasciende la diferenciación entre forma y contenido, planteándola desde la perspectiva del enfoque sistémico, donde la obra artística se constituye a partir de las interrelaciones entre el sistema estilístico y los sistemas narrativos o no narrativos. En la práctica este principio resulta muy útil, y es más coherente con las dinámicas pragmáticas de investigación, pues al tiempo que indagamos sobre las estructuras de narración, estamos inter-relacionando esos modos de narrar con opciones estilísticas que tienen que ver con las directrices estéticas desde las cuales filmamos.

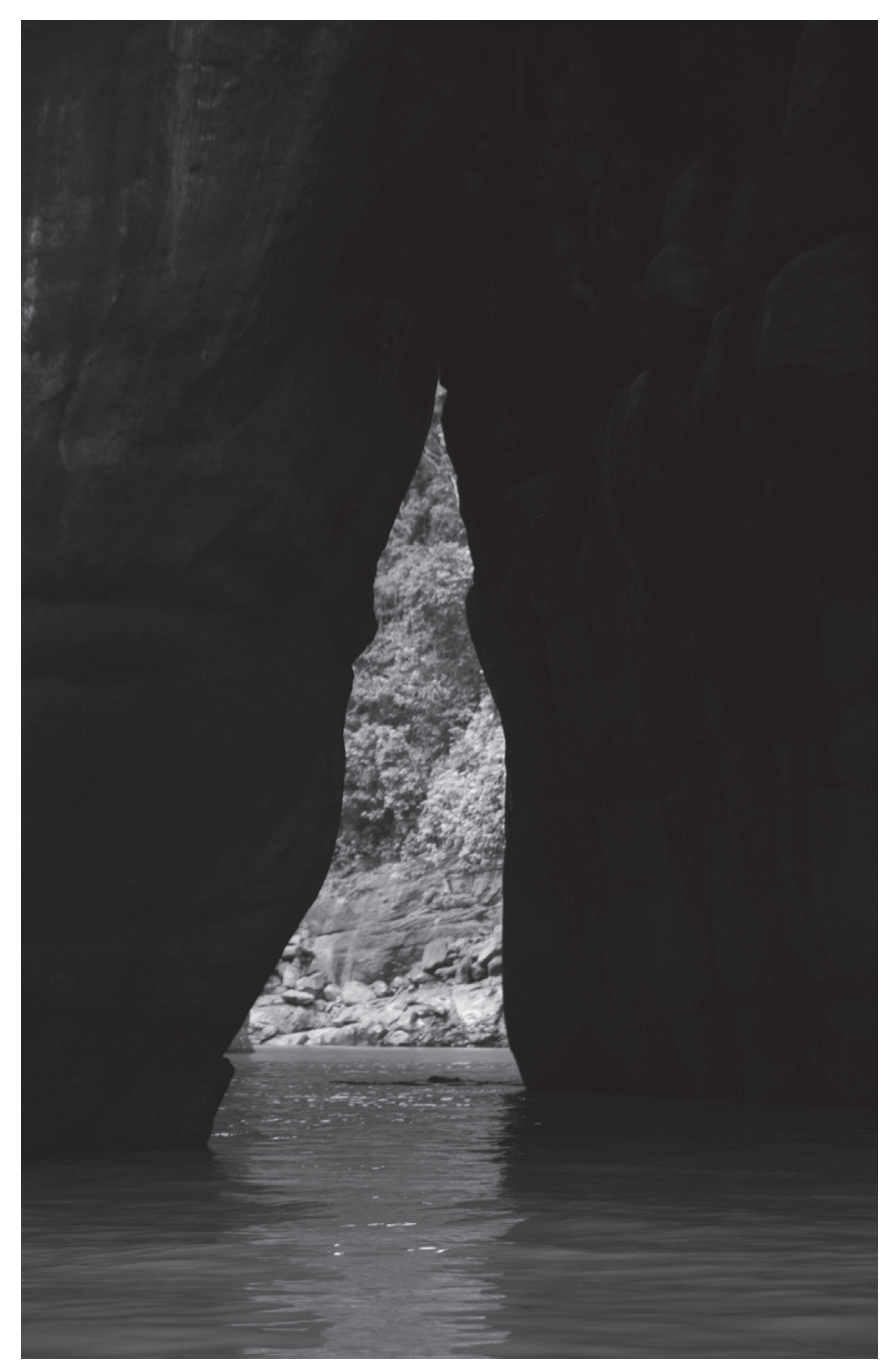

Aparentemente, con un libro tan bien documentado el problema de la investigación se simplifica, pero si se piensa orientar un proyecto audiovisual, donde hay un tiempo límite de minutos de duración, la situación se complica. La alternativa es desglosar el texto en unidades temáticas, indagar los potenciales audiovisuales expresivos y confrontarlos con la investigación de campo para auscultar el dispositivo narrativo más conveniente, en términos audiovisuales. También era fundamental definir qué era lo que me interesaba decir y trasmitir con el documental, en qué territorios se iba a filmar, qué comunidades indígenas serían prioritarias, sobre cuáles conocimientos íbamos a centrarnos, cómo aproximarnos a las comunidades, cuál sería nuestro punto vista, cómo serían las estrategias de filmación y los modos de representación audiovisual que adoptaríamos. Sabía que estos interrogantes, debían estar implícitos en el dispositivo que harían parte de un proceso en el que pudiéramos delimitar una directriz clara, personal y honesta, sin perdernos literalmente en la selva de información que nos rodeaba. 
En este proceso de investigación fue fundamental el apoyo de Cecilia Orozco y Omar Dorado, quienes aparte de ayudarme a desglosar el texto, ampliaron las referencias bibliográficas incluyendo otras obras escritas sobre la zona, como El Bejuco del Alma, que había escrito el propio Schultes, La Vorágine de José Eustasio Rivera y Desana: Simbolismo de los indios Tukano del Vaupés de Gerardo Reichel-Dolmatoff, también incorporaron los mapas de la zona, las comunidades, sus costumbres y sus lenguas, entre otros. Posteriormente me ayudaron a entender que la directriz era el seguimiento de los conocimientos en torno a algunas dietas alimenticias, y el uso de psicotrópicos, como la coca, la ayahuasca y el complejo veneno del curare. También apoyados en mapas, indagamos el contexto geográfico y las rutas potenciales. Decidimos que la figura de Schultes como personaje evocado era importante como referencia, pero la mirada debía focalizarse en un homenaje a los conocimientos indígenas. En una primera ronda de ideas, íbamos a involucrar varios países de la llanura amazónica. Esta perspectiva ampliaba los horizontes para financiar la producción y era evidente que estábamos ante un documental que podía ser de interés internacional.

La tarea inmediata era asumir la experiencia del documental, para conocer el territorio y a largo plazo, escribir un guion literario de ficción inspirado en el libro. Esta situación nos permitía abordar un proyecto documental con plena independencia. Es decir, no estábamos amarrados a una referencia evocada desde el imaginario literario de un refinado escritor canadiense, sino que teníamos mayor libertad para interpretarla. De las referencias del libro consideramos también la puesta en juego de dos modos de investigación que Schultes había orientado en sus investigaciones y que se podía inferir de su planteamiento, cuando decía que sus verdaderos maestros no estaban en Harvard sino en la Amazonía. Esta frase irreverente con las comunidades cultas era mucho más fuerte si recordamos que eran pronunciadas en el contexto de los años cuarenta, cuando los conocimientos indígenas no tenían el reconocimiento que se les otorga hoy en las comunidades científicas. Los saberes indígenas amazónicos en general, eran despreciados hasta por sus propios gobiernos, que replicaban el imaginario mestizo, de ocultar sus rasgos indígenas, resignificando la palabra indio, como portadora de significados despectivos. Schultes había hecho su doctorado en Harvard y se movía entre los saberes de la investigación científica y los saberes tradicionales. En este sentido era una voz de prestigio y uno de sus grandes aportes consiste en haber valorado estos saberes y haber asumido la tarea de hacer memoria y registrarla para la posteridad. Esta situación ha sido leída desde otros ángulos, donde el trabajo científico de Schultes, estaría puesto al servicio de estrategias militares en el contexto de la Segunda Guerra Mundial. Es un hecho, y está consignado en el libro El Río (y en el documental) que la investigación por el río Apaporis, la emprende atendiendo una orden de la inteligencia del ejército estadounidense, cuando lo envían a buscar una variedad de semillas de caucho resistente a las plagas. En ese momento es tal la dependencia bélica del caucho, que si la Segunda Guerra Mundial se hubiese prolongado, el ganador habría sido el país que lo tuviera, y para ese momento los japoneses tenían el control de la Indias Holandesas que eran los mayores proveedores en el mundo. La otra perspectiva que no aborda directamente el libro, tiene que ver con el saqueo de saberes tradicionales de la Amazonía, que vincularía a los investigadores con empresas farmacéuticas multinacionales. Estas interpretaciones hacen parte del contexto real y del malestar que se puede sentir cuando se abordan estos temas, pues muchos de los que visitan la selva quieren sacarle partido. En esta misma perspectiva, yo como documentalista, también hacía parte de ese grupo de agentes externos a la selva, que se aproximan para sacar partido de ella. Era inevitable no pensar en esta situación y por eso lo consigné en el documental. $\mathrm{Al}$ respecto tuve varias conversaciones con Isidoro Cabrera, con Alfredo Molano y con Davis, y sería un aspecto que tendría que investigar y abordar en el proceso de realización del audiovisual. 
Como el proceso de indagación implicaba entender la mirada de Schultes, recordé que Davis me había regalado un ejemplar de The Lost Amazon (1994) donde analiza la odisea fotográfica de Richard Evans Schultes en Colombia. Schultes tenía una gran sensibilidad artística. Según Davis, se sentía discretamente orgulloso de sus fotografías, las llamaba pinturas. La riqueza de sus fotografías no se ampara únicamente en la composición, el manejo de la luz o el gesto, sino en su manera respetuosa de captar al otro, lo cual subliminalmente se evidencia en el modo de representación que empleaba, desde el propio emplazamiento de la cámara. Habitualmente los exploradores europeos o norteamericanos que visitan los territorios indígenas, son regularmente más altos y al obturar, encuadran por el visor en picada, minimizando al indígena o a la comunidad retratada. Schultes en cambio expresaba su admiración y respeto con su cámara. En algunos casos se arrodillaba ante ellos para registrarlos incluso en leves contrapicadas, magnificando los rostros, plumajes y atuendos de los chamanes. A esto se suma la validez de
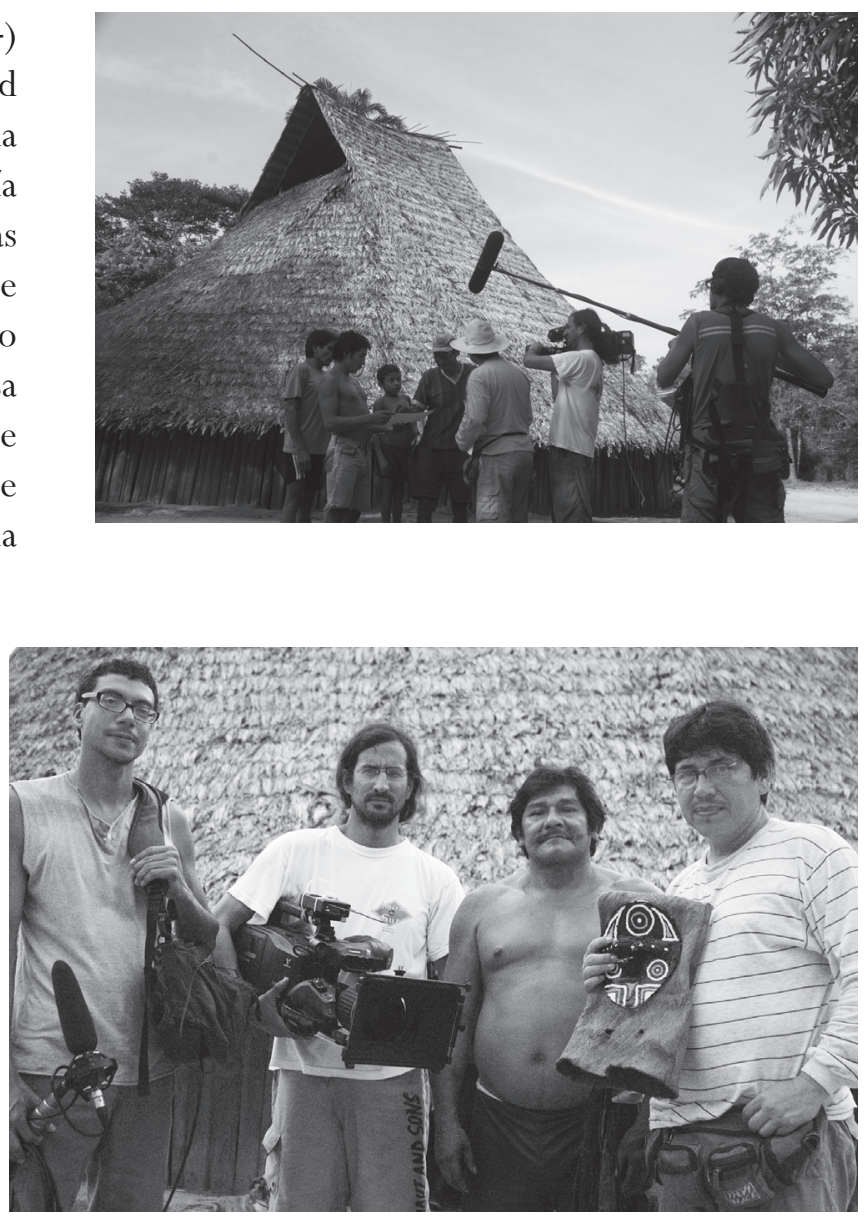
las primeras cámaras verdaderamente portátiles que salió al mercado en 1927, y que tenía una óptica no intercambiable de 80 milímetros, con un dispositivo de abertura amplia, ideal para las condiciones de luz baja en la selva. Adicionalmente, la abertura de la cámara exigía una distancia prudente, donde el fotógrafo está presente pero no es un intruso que invade la intimidad del sujeto. En cierta forma, este conocimiento de los registros fotográficos de Schultes, era un elemento inspirador que orientaba directrices para comentar, en su momento, con el camarógrafo que finalmente asumiría la fotografía de nuestro documental.

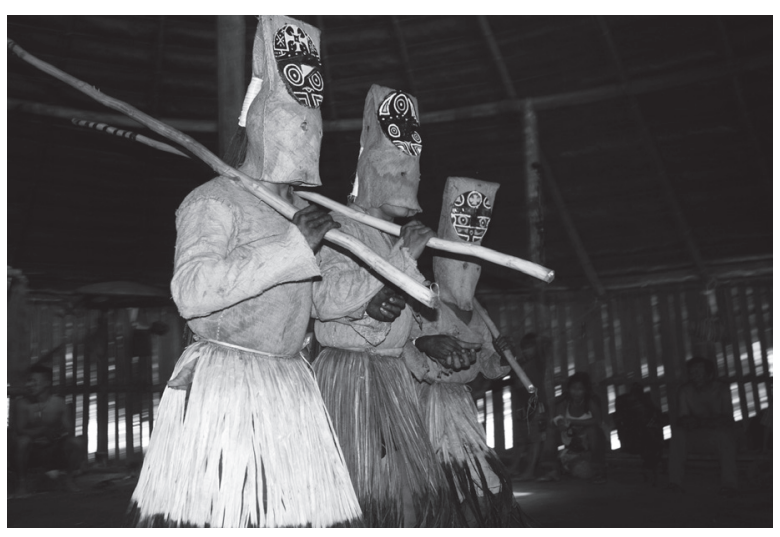

Fotografías: Diego Miguel Garcés 
A medida que se acercaba el tiempo límite de la convocatoria, el propósito de hacer una co-producción internacional se empezó a desplomar. Además quería trabajar de manera independiente con un equipo de colombianos que le daba validez y diferencia a nuestra mirada, pues habitualmente estos documentales los realizan directores y equipos de trabajo norteamericanos o europeos. Filmar en cualquier selva es complicado, pero en Colombia es un problema mayor por las adversidades del conflicto armado y la presencia del narcotráfico, el ejército, la guerrilla y los paramilitares. Pensamos en filmar el río Negro, el Vaupés, el Apaporis, el Putumayo y el Amazonas. Consulté el texto Apaporis, viajé a la última selva en compañía de Alfredo Molano, también hice la consulta con Andrés Hurtado, revisé su texto Colombia Secreta y hablamos por teléfono sobre las bondades y dificultades de la zona. De esa manera fuimos decantando que el lugar ideal era el Apaporis. Hablé con Davis, le pregunté por el Apaporis y me sorprendió cuando me reveló que no lo conocía. Estaba aterrado, en el libro describe el lugar como si fuera la palma de su mano. Luego me contó que Schultes le había hablado mucho de sus estancias con los cabillary, tanimukas y barazanos pero que nunca había podido viajar, y que para escribir el libro se había apoyado en las fotografías y los relatos que le habían narrado. Fue con sus palabras que se me reveló el dispositivo central del documental. Viajaríamos con Davis a Boston para recoger las cenizas de Schultes, luego iríamos a la Amazonía haciendo el recorrido por algunas comunidades del Vaupés y el Apaporis hasta el Jirijirimo, donde Davis regaría las cenizas de su maestro. Esta situación fue definitiva para amarrar la propuesta. El hecho de que el equipo que hacía la travesía llevara las cenizas, le otorgaba al documental una expectativa permanente y una carga simbólica y emocional, que a la postre aseguraba el final de la película con un ritual poético contundente. Además, Davis como personaje, ampliaba su dimensión, porque era el discípulo-escritor que viajaba a conocer un territorio de la llanura amazónica que había instalado en su imaginación pero que desconocía en la realidad. Por estas razones, cuando presentamos el proyecto lo titulé En busca del río.

Cuando investigamos más y me enteré en detalle del sitio del que me había antojado, empecé a sentir cosquillas en el intestino. El problema era entrar y salir con todo el equipo de filmación, incluido Davis, porque el lugar era una zona vedada para filmar. El azar nuevamente me guió, y en una reunión imprevista me encontré con un amigo que estudió en la Patricio Lumumba y trabajaba como médico en la Amazonía. A través de una cadena de amistades, me contactó con Juan Guevara, un antropólogo que llevaba más de veinte años trabajando en el Vaupés. Hablamos sobre el proyecto, estaba muy entusiasmado, me tranquilizó de los peligros, me compartió algunos de sus escritos ${ }^{8}$ y me reafirmó la necesidad de ir al Apaporis. Luego socializó con las comunidades y una semana antes de cerrar la convocatoria, consiguió una carta donde las autoridades indígenas del Jirijirimo permitían filmar en la zona.

Unos meses después, sustentamos el proyecto y por fortuna nos asignaron el apoyo económico que implicaba entregar un documental de 52 minutos. A partir de ese momento casi todo lo que pasaba por mis ojos y oídos lo miraba a través del documental. 
Cuando preparaba las clases, me cuestionaba las estrategias de narración, la importancia del sonido y los modos de representación. Habitualmente el cine norteamericano ha representado a las demás razas distintas a la blanca, como el otro, como sujetos peligrosos, belicosos, tontos. Tal como lo plantea Guardiola (1995) en su texto Otras miradas, otras representaciones, es evidente que se trata de una marginación consciente por parte de la industria audiovisual, que ha perpetuado estereotipos y negado identidades. Desde los orígenes del cine, el propio Griffith en 1910, con el film Ramona, instaló la representación de los nativos en la más ingenua tradición de Hollywood, donde narraba la trágica historia de amor entre una mestiza y un indio. Desde entonces, las imágenes de los nativos fluctúan entre el más noble y leal de los sirvientes y el peor de los bandidos. Esta visión romántica se ha perpetuado hasta el cine contemporáneo, afianzándose en diversos géneros como el western, la comedia y el drama. En cierta forma, la representación de los personajes latinoamericanos es una extensión de esa mirada. Para los norteamericanos de la frontera sur para abajo todos somos mexicanos. En consecuencia, si requieren un personaje colombiano, perfectamente puede interpretarlo un puertorriqueño, peruano, cubano o mexicano. En cierta forma la mirada que existe sobre el mestizo es una extensión del indígena, que es una especie de imbécil o desadaptado que no puede pensar por si mismo, o en el mejor de los casos son personajes bondadosos, y solo hábiles para la servidumbre.

No obstante, a partir de los años sesenta aparecen ciertas rupturas estéticas multiculturales y raciales que alteran el panorama cinematográfico convencional. En el contexto indígena, recordaba que Jorge Sanjinés en Bolivia, hizo algunas indagaciones con comunidades indígenas, proyectando películas clásicas norteamericanas, y ellos no entendían, por ejemplo, el llamado plano-americano, que corta a los personajes a la altura de las rodillas, porque les cortaban a los personajes los pies en la tierra. Desde el punto de vista indígena era absurdo que los registraran sin tener los pies en la pachamama ${ }^{9}$.

Exploré otras opciones de representación inspiradas en el documental etnográfico que plantea una relación particular entre el hombre y la naturaleza. Inevitablemente revisé la referencia legendaria de Robert Flaherty en Nanuk El Esquimal, pensé en su puesta en escena participativa, en su concepción del montaje desde el momento en que filma, en su intervención recursiva para hacer visible y filmable el interior de un iglú. Revisé The River, escrito y dirigido por Pare Lorenz sobre el río Missisipi, más que la narración en off, me interesaron sus registros fotográficos y me reafirmó la conveniencia de un río como dispositivo narrativo. En ese momento empezó el Diplomado en Documental de Creación ${ }^{10}$ en Cali, y me aproximé a las referencias francesas del cinema verité, especialmente de los filmes de Jean Rouch, donde la cámara es un agente catalizador de los acontecimientos que se filman. Me interesaba esta postura para algunas secuencias, como el registro de ceremonias religiosas. Pero además, me reafirmaba la idea de emplear una segunda cámara, para tener un plan b del registro del proceso de filmación. Me llamaba la atención la manera como Jean Rouch actualiza la cámara viviente, reviviendo la mirada del cine-ojo. De manera determinante, siempre me ha entusiasmado la postura de Dziga Vertov sobre el cine, para captar la vida de improviso, sin actores, sin maquillaje, sin 
vestuarios artificiales, con sus contradicciones frente a la puesta en escena y con la disposición amplia para dinamizar la narración, asumiendo la intervención creativa de un montaje, que no oculta ni su presencia, ni su intervención. También era inevitable tener la referencia del cine directo, no solo por la importancia narrativa del sonido directo, sino porque plantea el principio de observación, a través de una cámara que sigue a los personajes, que sabe tanto como ellos y que va conduciendo al espectador desde su misma perspectiva. Esta postura reafirmaba la necesidad de establecer una relación respetuosa, colocando la cámara y el equipo de filmación al servicio de los personajes.

Me preocupaba la interpretación narrativa y estilística de las ceremonias, particularmente la toma de yagé. Había mucha información literaria y científica sobre la representación de los trances psicotrópicos y revisé con especial interés los materiales de Víctor Masayeesva, que utiliza el video para realizar ensayos poéticos y visuales sobre la cultura y las tradiciones de los nativos norteamericanos, donde desafía los fundamentos del documental etnográfico, basado en la

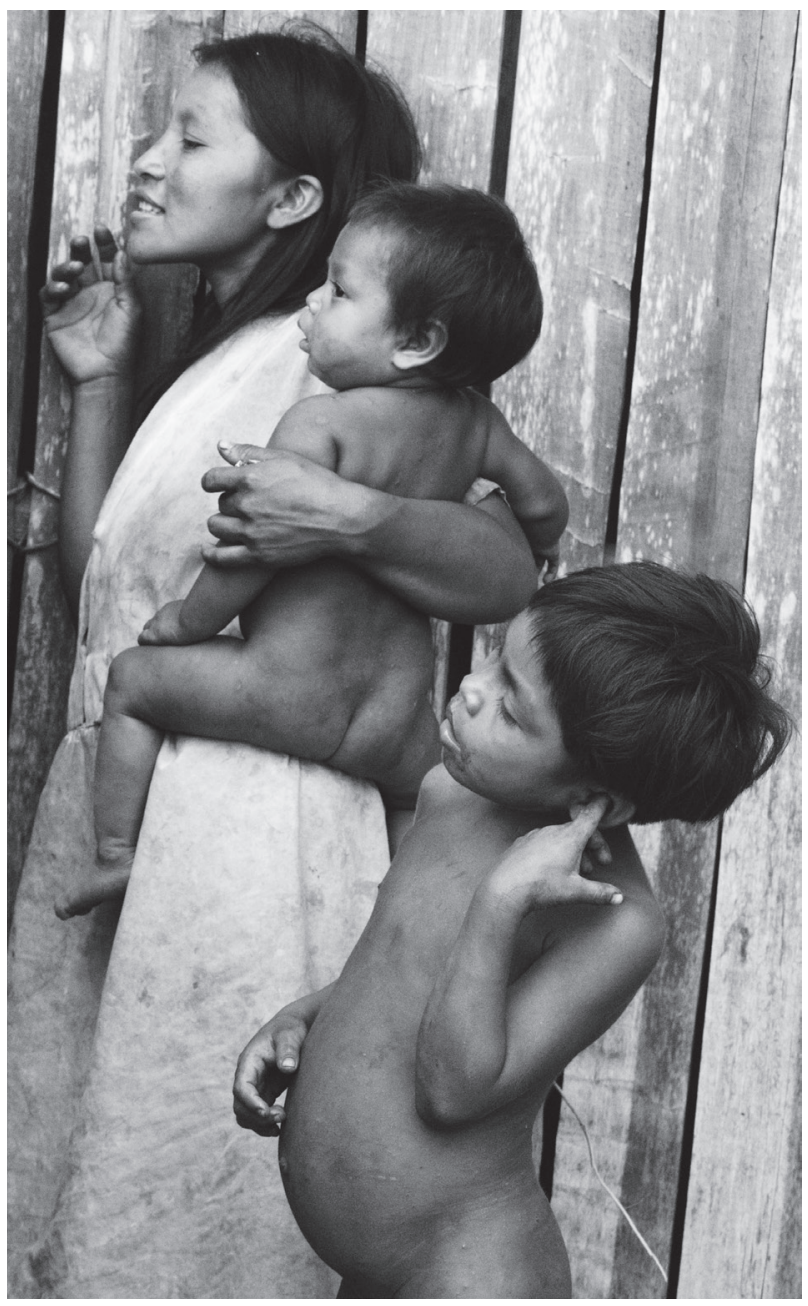
interpretación y la imposición cultural.

Paralelamente, reflexiono sobre el punto de vista que debo asumir. Revisé las elegías documentales de Sokurov. Tenía claro que no era, ni me interesaba aparecer como antropólogo, botánico o indígena. Así que decidí que estaría fuera de cuadro, acompañando a Wade Davis, que sería el narrador del diario de viaje.

En todo este proceso también me acompañó Lina Lazo como asistente de dirección, Cesar Salazar como sonidista y Mauricio Vidal como director de fotografía. Sé que en la filmación no hay tiempo para repetir o dar explicaciones y finalmente ellos fueron los cómplices que me ayudaron a narrar la propuesta. Intercambiamos ideas, películas y experiencias. Entretanto seguía en conversaciones permanentes con Juan Guevara que me envió sus publicaciones, al tiempo que establecía una agenda de contactos de las comunidades, preparando nuestra llegada. 
Ella se había salvado, pero cuando esto ocurre, si el paciente no tiene la atención médica adecuada en 24 horas, el bicho logra romper la protección ocular y devora totalmente la córnea en un abrir y cerrar de ojos. También tenía los referentes literarios y documentales de los legendarios ejércitos de hormigas tamboches que en temporadas azotan la llanura amazónica arrasando con las plantas y los seres vivos que encuentran. El problema era que no podía echar marcha atrás porque era yo, el director del documental.

Faltando un mes, recibí una pésima noticia. Davis se comunicó con la viuda del profesor Schultes y se enteró que hacía dos semanas en una reunión familiar habían regado las cenizas en el jardín de la casa. Es decir, todo el dispositivo de narración que estaba amarrado a ese hecho simbólico, no era posible. Pensamos en algunos objetos simbólicos del profesor, pero nada tenía el mismo poder de las cenizas.

Cuando avanzaba la cuenta regresiva para iniciar el viaje, empezamos sistemáticamente a recibir negativas a los permisos. Las cartas de la comunidad autorizándonos a entrar eran insuficientes. Había que entrar por Mitú y hacer interlocución con los diversos agentes del conflicto armado. Como todo lo que está mal puede empeorar, nos llegó una razón perentoria. Si queríamos viajar por la zona del Apaporis que nos interesaba recorrer, no podíamos llevar ningún medio de comunicación para establecer contacto con el exterior. Es decir, no podíamos llevar teléfonos satelitales, ni radioteléfonos. Era una situación muy complicada, cualquier imprevisto de salud o accidente debíamos asumirlo bajo nuestro propio riesgo. En ese momento decidí que Wade Davis no debía viajar con nosotros, lo cual cambiaba por completo el proyecto, porque era dejar de lado al narrador y guía de la historia. Él no tenía miedo de viajar, pero era una decisión correcta, al no poderle ofrecer la seguridad que requería. En estos casos uno llega a pensar que la investigación que tanto tiempo y esfuerzo demanda es inútil, porque una cosa es lo que el documentalista imagina y otra lo que enfrenta cuando filma. Sin embargo ¿qué tal si no se investigara? Regularmente en esos casos reina el caos. La investigación funciona como una especie de gimnasia mental y permite que uno tenga un repertorio de planes de contingencia. Después de dar tantas vueltas, el instinto se aviva y si se aprende a valorar los problemas, es posible sacarles partido, porque justamente esos obstáculos son los que hacen de este trabajo un oficio fascinante, que se parece a la vida. Lo aburridor debe ser hacer documentales con formatos donde todo está estandarizado. En el caso del documental En busca del río, al no tener el dispositivo de llevar las cenizas al Jirijirimo, tenía un plan alternativo que eran las fotografías. Se me ocurrió que la estrategia era llevarlas y enseñarlas en la travesía para saber qué había ocurrido con esos hombres y esas culturas que había registrado Schultes hace 40 años, con la esperanza de que alguien las reconociera. Se había desplomado un dispositivo, pero al caerse, se había hecho visible un documental quizás más coherente con mi intensión de hacer un homenaje a las comunidades del Apaporis. En el caso de Davis, decidí que si no había podido invitarlo a la selva, le llevaría lo filmado a su casa en Washington. Por supuesto, esa claridad no se vislumbra con tanta inmediatez. Se requiere un tiempo de duelo para entender y valorar las nuevas alternativas, sobre todo en este caso que afectaba la estructura de la narración del proyecto. Pero además debía decidir rápido, porque el cronograma no se podía alterar y debía aprovechar el tiempo del receso académico para filmar el documental.

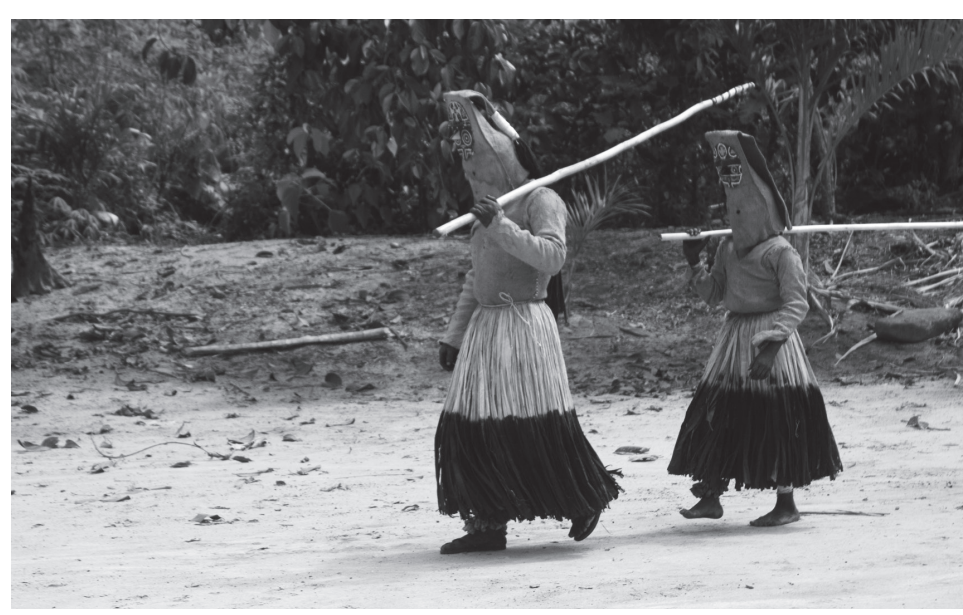


Durante el rodaje se presentaron múltiples inconvenientes, solo quiero reseñar que después de los 21 días de rodaje, no logramos filmar todo lo que hubiera deseado. En primer lugar porque no todo lo que uno mira lo puede registrar el ojo de la cámara y de otro lado, porque en varios lugares no había energía y debíamos filmar lo estrictamente lo necesario. La transformación entre lo que investigamos y lo que encontramos fue abismal. Con frecuencia lo filmado superó lo que habíamos previsto, pero en el fondo, la mayor parte de lo investigado estaba en el subtexto de lo que encontramos. La mayor sorpresa que tuve es que a medida que nos internábamos en la selva, el fantasma apocalíptico del infierno verde se había esfumado, porque antes que el infierno encontramos lugares paradisíacos, de gente sencilla y amable con quien hicimos una entrañable amistad. El documental da cuenta de esa metamorfosis emocional que sentimos, pero además advertíamos que esa imagen del indígena nostálgico, triste y amargado, no tenía nada que ver con los tanimucas, los cabillary o los barazanos. Son gente muy alegre, que no tiene nada que ver el imaginario que tenemos desde el interior, donde la selva ha sido el patio trasero. Posteriormente, en las vacaciones de medio año filmé en Washington con Wade Davis y viajé a Leticia para hacer unos planos adicionales.

Luego vendrían dos años de trabajo con Mauricio Vergara, el montajista. Hicimos más de 20 versiones diferentes. El montaje es el escenario final donde hay que investigar, mirar, escuchar y revelar la estructura de película que se quiere contar. Mauricio es un egresado nuestro, que tiene la virtud de ser un meticuloso montajista, pero además es músico. En las primeras versiones no había narrador, porque no lo había previsto en la investigación, sin embargo al buscar una estructura para un largometraje que generara expectativas, empecé ensayando provisionalmente con mi voz y finalmente lo provisional terminó siendo definitivo. En ese proceso aplicamos a varias convocatorias y esto me obligó a escribir y conocer mejor el trabajo que habíamos filmado. Es extraño, pero el acto de escribir, que no está asociado directamente a los sonidos o las imágenes ayuda notablemente a comprender nuestras propias ideas. En ese camino ganamos algunos premios que nos posibilitaron terminar el documental en $35 \mathrm{~mm}$.
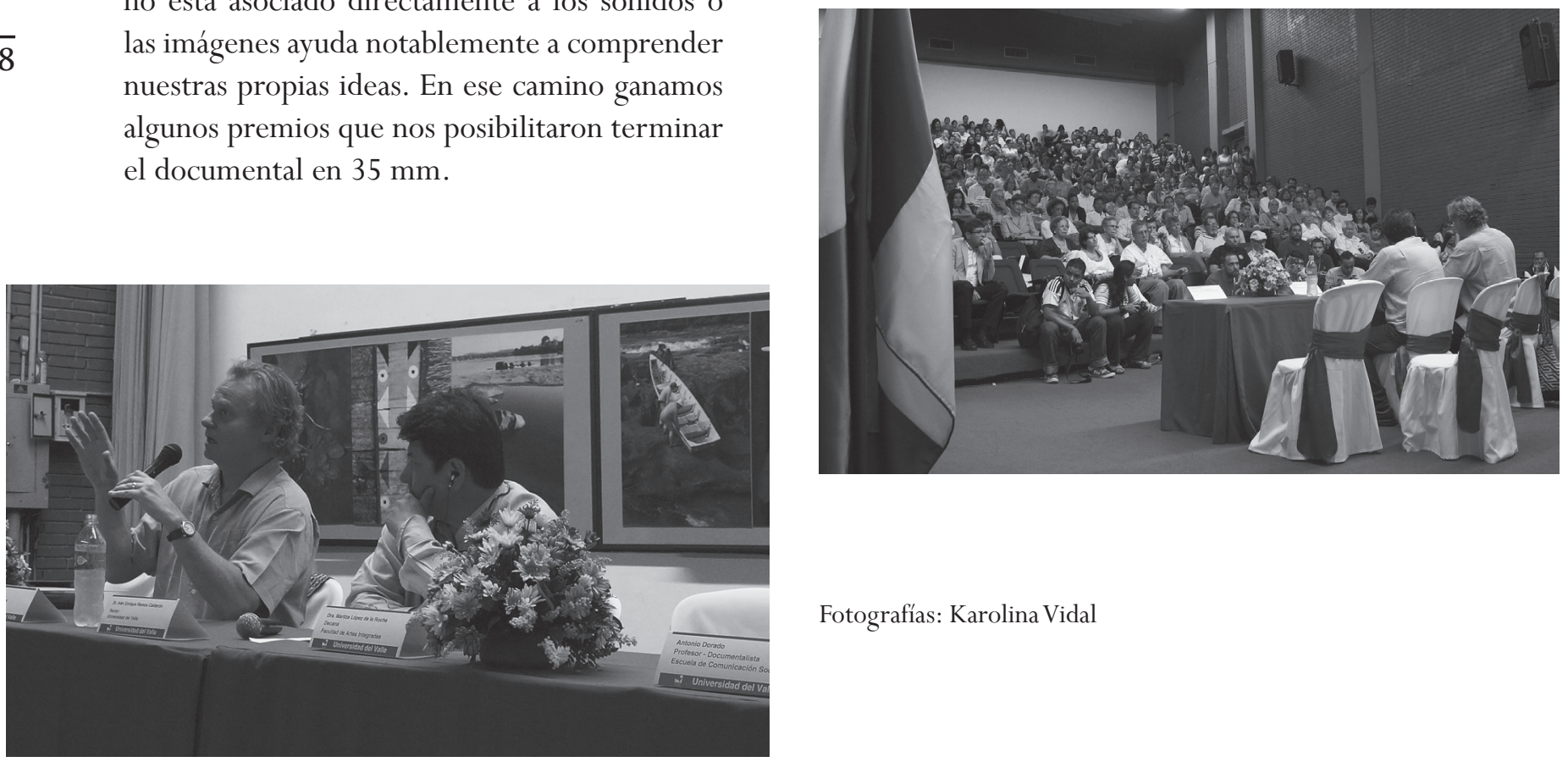

Fotografías: Karolina Vidal 

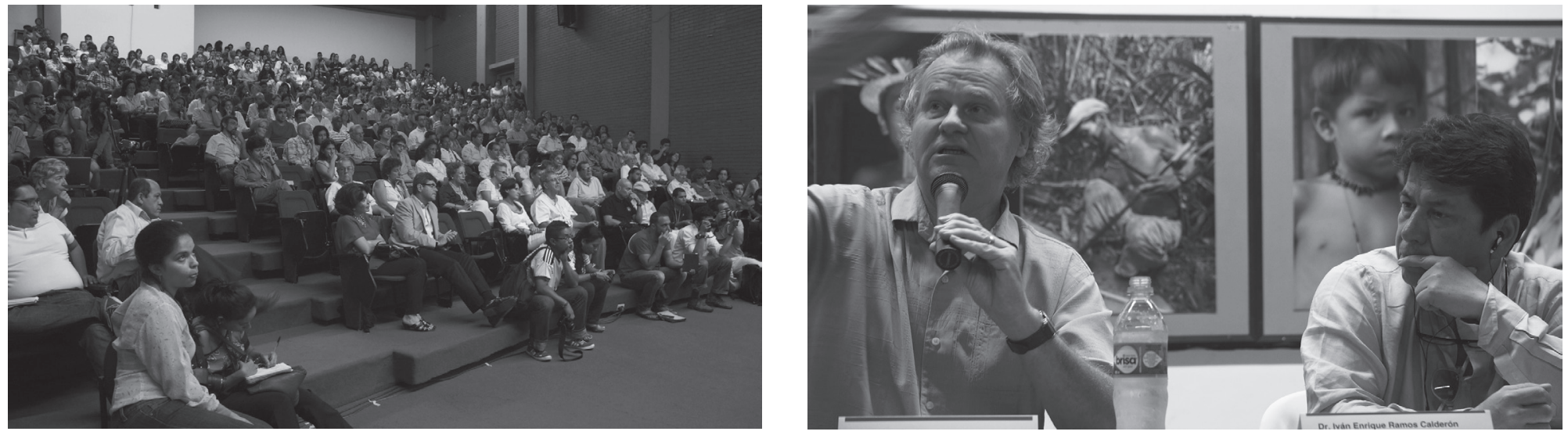

En los documentales, el proceso de investigación es muy dispendioso y puede resultar engorroso, pero si uno lo hace por pasión, es placentero imaginar secuencias y jugar con la edición de imágenes y sonidos. Es un proceso gratificante que invita a pensar, a imaginar, a buscar asociaciones, a ampliar referencias, a crear hibridaciones, a buscar otras lecturas, fuentes y soportes. En mi caso, siempre trato de imaginar las películas en su máximo esplendor, porque finalmente cuando uno empieza a hacerlas, se van desmoronando y terminan siendo las ruinas de lo que uno quiso hacer, por eso es importante magnificarlas desde el inicio, de tal forma que después, cuando se vayan marchitando, sigan siendo interesantes y uno no sienta vergüenza de haber trabajado en ellas.

Para finalizar, debo comentar que una experiencia fundamental fue el hallazgo de la música. Tan pronto logramos una versión digna, nuestro amigo en Los Ángeles contactó al manager de Philip Glass ${ }^{15}$ para componer la música. El señor Glass vio la edición, aceptó y nos envió una lacónica nota que decía Es un film hermoso y lleno de poder. Sin embargo cuando nos enviaron los costos, el propósito se derrumbó, porque sobrepasaba incluso los recursos invertidos en todo el documental, así que empecé a mirar otras opciones. En el Festival de Cartagena me encontré con Alejandro Ramírez, que había sido estudiante de la Escuela de Música de la Universidad del Valle, y que estaba interesado en el proyecto. Buscando el acompañamiento orquestal, le enseñé el trabajo a Mariana Garcés y me ofreció el apoyo de la Orquesta Filarmónica del Valle, con el propósito de hacer un preestreno en el Festival de Arte del 2009. Cuando empezamos a orientar la música, con Alejandro y el Montajista, Alejandro pensó en los coros y le solicité el apoyo al profesor Héctor González de la Escuela de Música de la Universidad del Valle y a los pocos días hicimos la presentación más emotiva que se haya hecho del documental, porque la música en vivo significó una experiencia que dimensionó el trabajo de todo el equipo.

El corte de la película se terminó en el 2010, pero nadie creía que podía tener interés para el público, después de muchos intentos, logramos convencer a distribuidores y promotores y se estrenó el 17 de febrero del 2012 con once copias ${ }^{16}$. A la fecha es el documental más visto en salas de cine en Colombia. Ha tenido gran acogida en muchos espacios nacionales e internacionales. El narrador ha sido objeto de valoraciones positivas, 
pero también ha sido objeto de críticas. Independientemente de los resultados, orienté la película a mi manera con el apoyo de un equipo numeroso que se advierte en los créditos. Por supuesto, esta independencia la he logrado por el respaldo y complicidad que he tenido de la Escuela de Comunicación Social, y de la Universidad del Valle para emprender este tipo de propuestas.

Cuando se presentaba en la salas de cine, entraba para leer un prólogo y orientar el homenaje a las comunidades del Apaporis. Como pasaba de una sala a otra, en ocasiones llegaba tarde y me quedaba hasta el final. Mi sorpresa era que al terminar la exhibición, muchos espectadores motu proprio se levantaban de sus puestos y aplaudían la sabiduría de estos hombres de la selva. Sé que en Colombia se aplaude de manera muy extraña, incluso cuando aterriza un avión, pero cuando el público reacciona de esta manera en una sala de cine, es porque los documentales que hablan de nuestros pueblos, reclaman un lugar en la pantalla.

\section{Notas}

${ }^{1}$ Este artículo es un producto que se originó a partir de la investigación Aproximaciones al Paisaje y las Bellezas Escénicas Naturales. Río Apaporis, desarrollada en la Universidad del Valle como resultado de un proyecto de investigación en Artes y Humanidades a través de una convocatoria interna de la misma institución (2009). El objetivo era crear a partir del enfoque sistémico una estrategia de investigación interdisciplinaria para analizar el paisaje amazónico colombiano a partir de una mirada geológica, jurídica y estética. He escrito este artículo pedagógico que yuxtapone mi rol de docente, investigador y realizador audiovisual con el propósito de propiciar una reflexión sobre los procesos de investigación en el documental, a partir la experiencia del largometraje documental Apaporis, Secretos de la Selva filmado en el nordeste amazónico.

${ }^{2}$ Magíster en Literatura colombiana y latinoamericana de la Facultad de Humanidades de la Universidad del Valle, Especialista en prácticas audiovisuales y Comunicador Social de la Escuela de Comunicación Social de la Universidad del Valle. Cali, Colombia. Correo electrónico: jose. dorado@univalle.edu.co

${ }^{3}$ El documental Apaporis ha estado en numerosos festivales a nivel nacional e internacional, en Estados Unidos, México, Alemania, Inglaterra, Escocia, Polonia, Argentina, Brasil, Perú, España, Italia, Francia, Suiza y Colombia.

${ }^{4}$ Según las cifras suministradas que aparecen consignadas en el Anuario Estadístico Colombiano (Ministerio de Cultura Colombiano, p. 25), Apaporis registró una asistencia de 44.177 espectadores. Es una cifra superior a todos los documentales colombianos exhibidos en pantalla, pero también una cifra que supera a numerosas piezas de cine colombiano de ficción.

${ }^{5}$ A partir de ese momento el profesor Isidoro Cabrera ha sido un aliado permanente del proyecto. Al haber sido asistente personal del profesor Richard Evans Schultes, en sus andanzas por la Amazonía, ha sido una fuente de primera mano. Sus recomendaciones fueron muy importantes para los viajes a Mitú y al río Apaporis.

${ }^{6}$ La Dirección Cinematográfica es el organismo del Ministerio Colombiano de Cultura, que a partir de la puesta en marcha de la Ley 814 de 2004, conocida como la Ley del Cine, tiene la función de ejecutar los recursos mediante convocatorias públicas. En el año en que aplicamos no había recursos para largometrajes documentales, casi que de antemano no se pensaba que los documentales tuvieran un lugar en la pantalla.

${ }^{7}$ Cuando cursé la Maestría en Literatura Colombiana y Latinoamericana, hice varios trabajos al respecto y particularmente la tesis de grado Análisis de re-escritura cinematográfica de La Larga Vida Feliz de Margarito Duarte. 


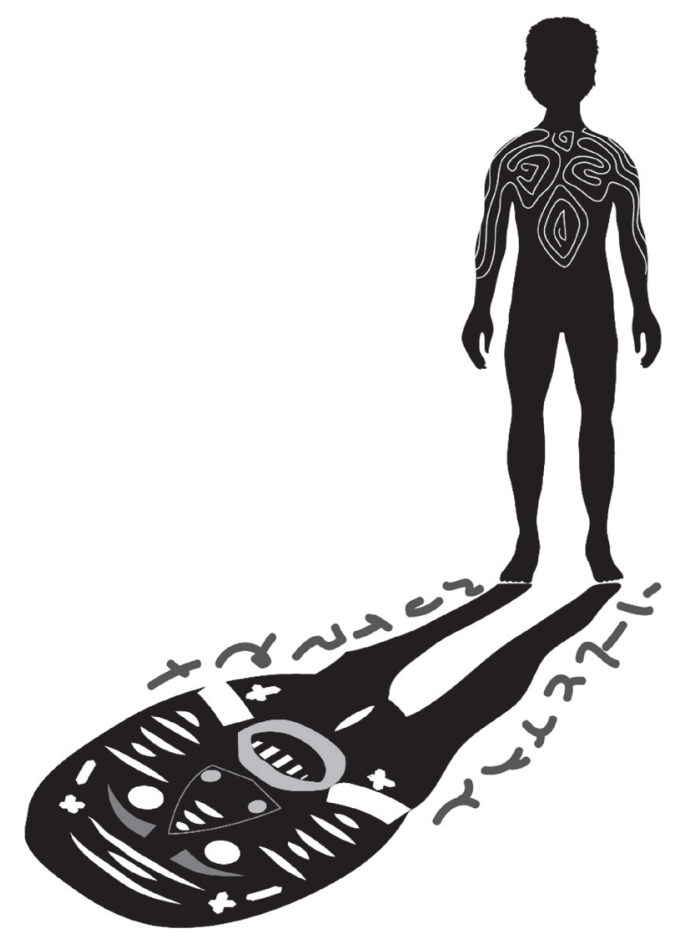

${ }^{8}$ Juan Guevara estudió Antropología en la Universidad Nacional y llevaba más de treinta años trabajando en la zona con diferentes comunidades indígenas. Su apoyo fue fundamental para llevar a cabo el proyecto.

${ }^{9}$ La relación con comunidades que nos han sido expuestas a la tradición de consumo audiovisual, ha arrojado en diferentes lugares, lecturas particulares sobre la imposición de una estética y narrativa fílmica.

${ }^{10}$ El Diplomado en Documental de Creación ha sido un espacio de formación determinante para que realizadores, docentes y espectadores del sur-occidente colombiano. Participé en calidad de profesor, pero ha sido un espacio académico que nos ha permitido tener interlocución con realizadores, historiadores y teóricos de otras latitudes, entorno al potencial y las dinámicas de las tendencias narrativas del documental.

${ }^{11}$ Documental El Baile del Muñeco (Pablo Mora, 2003) fue un referente obligado porque era una experiencia relativamente reciente, pero además porque el fotógrafo y camarógrafo Mauricio Vidal había hecho la cámara en ese proyecto y en ambos documentales se compartía el ritual del baile del muñeco o de a pupuña.

${ }^{12}$ La primera filmación en cine sobre el río Apaporis la había hecho el geólogo Thomas Van der Hammen en los años cincuenta cuando recién llegado al país, el profesor Richard Evans Shultes lo invitó a la zona y Van der Hammen filmó en super 8 .

${ }^{13}$ Visité los archivos de Patrimonio Fílmico y entre los materiales Rito Alberto Torres nos recomendó un fragmento que habían rescatado de una película encargada a la Ducrame Films por la United States Rubber Development Corporation, denominada Rumbo al Corazón de la Selva (1945).

${ }^{14}$ Alfredo Molano realizó varios documentales para la televisión nacional, en una serie que denominó Travesías. Visioné cuidadosamente ese trabajo, pero antes de viajar hablé con Molano y con María Constanza Ramírez, sobre las potencialidades y dificultades del viaje. Estas orientaciones nos ayudaron enormemente a comprender la situación del territorio, pues la información del documental se ampliaba en las crónicas que escribieron, y nos permitieron incluso identificar personajes que luego contactaríamos, cuando visitamos la zona.

${ }^{15}$ El norteamericano Philip Glass es uno de músicos de mayor reconocimiento en el mundo del cine. Su interés de participar en el documental, fue un aval que nos alentó, pues su presencia afianzaba el prestigio del trabajo.

${ }^{16}$ Las copias se hicieron en $35 \mathrm{~mm}$ en un laboratorio en Los Angeles. Esto garantizaba una buena calidad de proyección. 


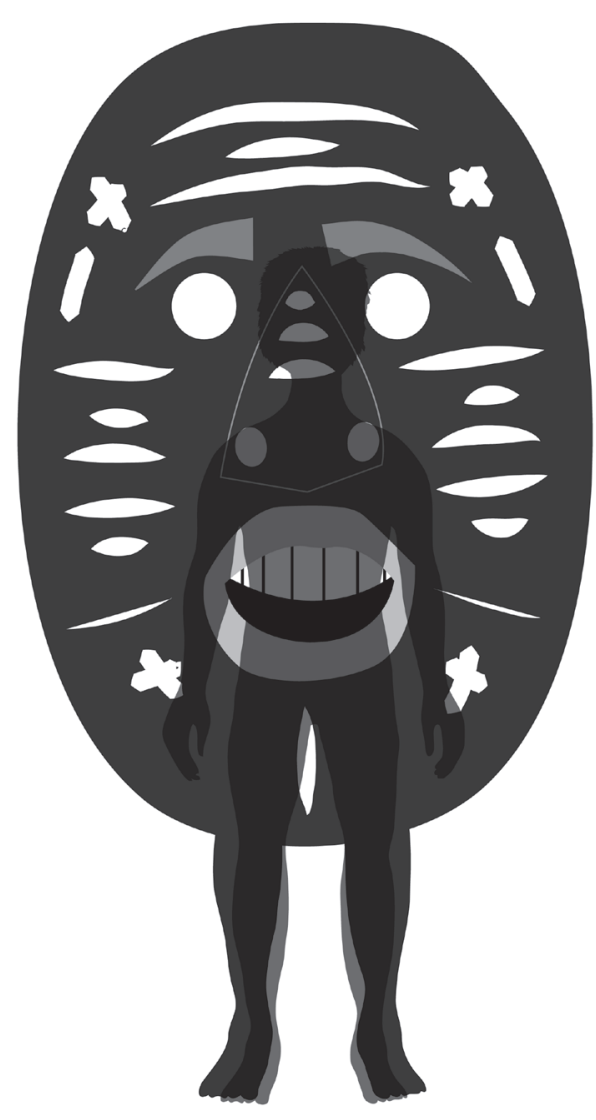

\section{Referencias}

Davis, W. (2005). El Río. Exploraciones y descubrimientos en la selva amazónica. Bogotá: El Áncora Editores Fondo de Cultura Económica.

Davis, W. (1994). The Lost Amazons. San Francisco, California: Insight Editions.

Davis, W. (1986). La Serpiente y el Arco Iris. Buenos Aires: Círculo de Lectores.

Bordwell, D. \& Thompson, K. (1995). El Arte Cinematográfico. Barcelona: Editorial Paidós.

Bluestone, G. (1957). Novels into Film, University of California Press, Berkeley.

Burroughs, W. Cartas del Yagé. Buenos Aires: Ediciones Signos S. R. L., 1971.

Frago Perez, M. (2005). Reflexiones sobre la adaptación cinematográfica desde una perspectiva iconológica en: Comunicación y Sociedad, Volumen XVII. Pamplona: Universidad de Navarra.

Guardiola, J. (1995). Otras miradas, otras representaciones, en Historia General del Cine. Volumen XII: El cine en la era audiovisual . Madrid: Cátedra.

Guevara, J. (1984). Etnodesarrollo y Medicina Indígena Ecológica. Mitú: Departamento Administrativo de Salud del Vaupés.

Hurtado, A. (2005). Colombia Secreta. Bogotá: Villegas Editores.

Kapuscinski. (2007). El Encuentro con el Otro. Barcelona: Editorial Anagrama.

Konrad, J. (1996). El Corazón de la Tinieblas. Veracruz: Universidad Veracruzana.

Rivera, J. E. (2000). La Vorágine. Santafé de Bogotá: Panamericana Editorial.

Reichl-Dolmatoff, G. (1986). Desana: Simbolismo de los indios Tukano del Vaupés. Bogotá: Procultura.

Molano, A., Ramírez, M. C. Apaporis, viaje a la última selva. Editorial Planeta, Bogotá, 1997.

Schultes, R. E., Raffauf R. F. (2004). El Bejuco del Alma. Los médicos tradicionales de la Amazonía colombiana, sus plantas y sus rituales. Bogotá: El Áncora Editores y Fondo de Cultura Económica. 


\section{Filmografía}

Amaya, A., Lamy, J. C. (productor) \& Rendón, C. y Lamy, J. C. (director). (1994). Los Nukak Makú: los últimos nómadas [cinta cinematográfica]. Colombia - Belgica: Audiovisuales - AVC Rainbow

Amaya, A., (productor) \& Molano, A.(director). (1992). Travesías, [cinta videográfica]. Colombia: Audiovisuales.

Camino, D., Herzog, W., Prescher, H. (productor) \& Herzog, W. (director). (1972). Aguirre, Wrath of God [cinta cinematográfica]. RFA: Werner Herzog Filmproduktion.

Coppola, F., Audrey, K. (productor) \& Coppola, F. (director). (1979). Apocalipsis Now [cinta cinematográfica]. USA: Zoetrope Studios.

Dorado, Jairo Alberto (productor) \& Dorado, José Antonio (director). (2010). Apaporis. [cinta cinematográfica]. Colombia: Fundación Imagen Latina.

Dziga V. (productor) \& Dziga Vertov (director). (1929). Chelovek s kino-apparatom [cinta cinematográfica]. URSS: VUFKU

Griffith, D. W (director). (1910). Ramona [cinta cinematográfica]. USA: Biograph Company.

Herzog, W., Rossellini, R., Saxer, W. Segler, W., Sipetic, L. (productor) \& Herzog, W. (director). (1982). Fitzcarraldo [cinta cinematográfica]. RFA: Werner Herzog Filmproduktion. Wildlife Films Peru.

Flaherty, R. (productor). Flaherty, R. (director). (1922). Nanook of the North [cinta cinematográfica]. U.S.A.: Les Frères Revillon, Pathé Exchange.

Lesoeur, Daniel y Dorado, José Antonio (productores) \& Dorado, José Antonio (director). (2010). Apaporis. [cinta cinematográfica]. Colombia: Fundación Imagen Latina.

Lorenz, P. (productor). Lorenz, P. (director). (1938). The River [cinta cinematográfica]. USA: Farm Security Administration.

Laad, D. (productor) \& Craven, W. (director). (1988). The Serpent and the Rainbow [cinta cinematográfica]. USA: Universal Pictures.

Masayesva, V. Jr. (productor) \& Masayesva, V. Jr. (director). (1992). Imagining Indians [cinta cinematográfica]. USA: Masayesva, $\mathrm{V}$. Jr.

Bardet, P. (productor) \& Sokurov, A. (director). (2001). Elegy of a Voyage [cinta cinematográfica]. Coproducción Francia-Rusia-Holanda; arte France Cinéma / Idéale Audience / Bereg Productions / Kasander Film Company.

Lopez, C., Quiroga, P., Santamaría, N. (productor) \& Mora, P. (director). (2003). Crónica de un baile de muñeco [cinta videográfica]. Colombia: Proimágenes.

Recibido: abril 15 / Aprobado: mayo 30 de 2014 